\title{
Exploring Factors Influencing Open Innovation Adoption in SMEs: The Evidence from Emerging Markets
}

\author{
Wilert Puriwat ${ }^{1}$, Suchart Tripopsakul ${ }^{2 *}$

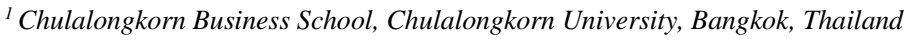 \\ ${ }^{2}$ School of Entrepreneurship and Management, Bangkok University, Bangkok, Thailand
}

\begin{abstract}
Open Innovation (OI) is among the vital innovation paradigms for assisting small and medium enterprises (SMEs) to effectively implement innovation initiatives. Drawing on the concepts of organisational agility and absorptive capacity with transaction cost theory, this study's goal is to investigate factors affecting the adoption of an Open Innovation (OI) orientation in Thai SMEs. Using data from 214 SMEs in Thailand, structural equation modelling validated the model and analysed the proposed hypotheses. The results show that organisational agility, economic and financial readiness and absorptive capacity relate positively to OI adoption and innovation performance. Organisational agility $(b=0.553)$ had the greatest influence on OI adoption, then economic and financial readiness $(b=0.405)$ and absorptive capacity $(b=0.387)$ followed. The results of mediation analysis also reveal that OI adoption partially mediates the effects of organisational agility and absorptive capacity on innovation performance. Our study provides a trailblazing empirical analysis of the major factors influencing SMEs' OI adoption and performance, extending knowledge of OI adoption by SMEs in emerging economies. The paper proposes a holistic framework for examining SMEs' OI adoption and performance, through the integration of organisational agility, absorptive capacity and transaction-cost concepts.
\end{abstract}

\section{Keywords:}

Open Innovation;

Organisational Agility;

Absorptive Capacity;

Innovation Performance.

\section{Article History:}

$\begin{array}{llll}\text { Received: } & 19 & \text { May } & 2021 \\ \text { Revised: } & 09 & \text { July } & 2021 \\ \text { Accepted: } & 23 & \text { July } & 2021 \\ \text { Published: } & 01 & \text { August } & 2021\end{array}$

\section{1- Introduction}

Innovation is one of the imperative strategic mechanisms for sustainable growth. Firms must innovate in response to changing customer needs, market structure and technology disruption. Innovation has emerged as a critical factor in the survival, growth and competitive advantage of SMEs [1,2]. The need for an ongoing process of innovation is not only vital for their survival; it can also trigger social and economic changes. Innovation is essential for sustainable growth and economic development [3, 4]. In emerging economies, most businesses are SMEs and important contributors to job creation and global economic development. Data from the World Bank [5] reveal that SMEs represent about 90\% of businesses and over $50 \%$ of employment worldwide, contributing $40 \%$ of national income (GDP). Both SMEs and innovation are important mechanisms for national economic development. A nation can achieve sustainable development through fostering SME innovation [4]. Open Innovation (OI) has become a widely recognised and implemented concept among large corporations. Applying OI may speed up and enhance organisations' innovation process and commercialisation of their innovations. Academics and scholars have explored the key factors and practices that stimulate the successful adoption of OI. Although recent literature suggests that adopting OI can help SMEs boost their innovation performance, the literature still lacks adequate evidence relating to OI from the SME perspective [4, 5].

\footnotetext{
${ }^{*}$ CONTACT: suchart.t@bu.ac.th
}

DOI: http://dx.doi.org/10.28991/esj-2021-01295

(C) 2021 by the authors. Licensee ESJ, Italy. This is an open access article under the terms and conditions of the Creative Commons Attribution (CC-BY) license (https://creativecommons.org/licenses/by/4.0/). 
SME adoptions of OI have garnered researchers' attention [6] in studies focused on OI approaches and practices. Realising OI as a new innovation paradigm is becoming more prevalent. OI utilises purposive knowledge inflows and outflows to expedite internal innovation and expand the markets for its external use [7, 8, 9]. It encompasses outside-in and inside-out technology and idea movements, dubbed 'technology acquisition and exploitation' [10, 11].

OI studies reveal firms' diverse behaviour patterns. Lee, Park, Yoon, and Park (2010) [12] found that OI implementation approaches and adoption models vary according to the size of the enterprise. SMEs benefit differently from OI [13]. Therefore, benchmarking the success of OI implementation cannot use the same criteria for large firms as for SMEs. Greater understanding of SME conditions and contexts would increase the chances of successfully implementing OI approaches. A scant understanding of how SMEs can adopt and implement OI requires more empirical evidence for clarification [14].

Numerous external and internal factors influence firms' innovation adoptions and practices [15]. Internal factors include size, age and research and development (R\&D) investment; external factors include technological advances and industry intensity. Both affect large multinational firms' innovation adoption $[10,15]$. While external factors influence SMEs' innovation adoptions in ways similar to those in large firms, most SMEs lack resources for R\&D, due to limited funding and knowledge. Despite attempts to provide empirical evidence for understanding firm innovation adoption, only a few studies focus on the context of SMEs in emerging countries, such as Thailand. Moreover, the lack of a holistic conceptual framework to determine factors influencing an OI adoption allows us to contribute a fruitful body of knowledge, by drawing on organisational-agility and absorptive-capacity concepts and transaction-cost theory, to better understand OI adoption and innovation performance in the SME context.

The remainder of this paper is structured as follows. Section 2 focuses on relevant literature concerning organisational agility, absorptive capacity, transaction cost theory and open innovation. Section 3 details some tentative propositions on OI adoption and innovation performance in SMEs and illustrates the research methodology utilised for data collection. Section 4 presents data analysis, results and discussion. Section 5 postulates a conclusion, and Section 6 details the study limitations and prospects for future research.

\section{2- Literature Review}

\section{2-1- Organisational Agility and Open Innovation}

Organisational Agility (OA) is a firm's ability to undertake unanticipated changes through immediate and innovative responses. Previous studies confirm that $\mathrm{OA}$ is one of the critical capabilities that helps firms properly capture current market trends $[16,17]$. OA is a multidimensional concept that scholars have classified by specific types, according to their different foci [18]. Bessant et al. (2000) [19] classify four vital OA dimensions: agile strategies, agile processes, agile linkages and agile people. Vázquez-Bustelo et al. (2007) [20] classify OA in five dimensions: agile human resources, technologies, value chain integration, concurrent engineering and knowledge management. Zandi and Tavana (2011) [21] classify organisational agility into three elements: strategic, operational and functional agility. Sambamurthy et al. (2003) [22] also identify three classes: customer, partnering and operational agility. Customer agility is leveraging customers' opinions to earn enhanced market intelligence [23]. Partnering agility is absorbing knowledge from business partners to embolden the firm's response to market requests. And operational agility refers to the ability to cope with volatile market changes using internal business processes and the execution of a product innovation plan to devise a new product design [24].

According to the dynamic-capabilities concept, OA can arise from the integration of strategic resources. Teece et al. (2016) [25] stand by this argument, stating that OI can embolden agility by enhancing and expediting novel product development, to meet upcoming market openings. Yet, OI and OA remain vague in terms of the relationship between them, and we ask again here what it is. Clearly, OA acts as an antecedent to OI adoption. By allowing access to versatile complementary knowledge, inbound OI diminishes experimentation-related risks and stimulates a firm's innovation engine, enabling flexibility when attempting fierce and radical innovation [26]. Utilising external resources helps firms to perpetually communicate and share knowledge, thus enhancing the spread of know-how [27]. Such a firm allows its managers to efficiently respond to external changes, ensuring the organisational structure's flexibility, necessary to predict and tend to future requirements [26]. Scuotto et al. (2017) [27] suggest that intensive inbound OI allows adequate internal proactive efficiency and continuity for environmental signal scanning, enabling a dynamic-management business process that allows for greater market capitalisation and operational adjustment agility. Besides inbound OI, $\mathrm{Hu}$ et al. (2015) [28] postulate that outbound OI enables firms to exploit emerging market opportunities through efficiently developing market-related knowledge. Additional market opportunities facilitate firms' obtaining and assessing sufficient customer feedback and scrutinising competitors' activities, ensuring efficient decision-making in operational process adjustment and market capitalisation [29]. Firms with outbound OI usually must watch for a wider range of technological developments, to acquire potential internal opportunities for drastic innovation [28]. Broadly scanning for technology resources can open opportunities for addressing firm imperatives. Operational exploitation can also enhance firm abilities to utilise emerging market opportunities through continuous adoption [26]. 


\section{2-2- Absorptive Capacity}

Overby et al. (2006) [30] establish absorptive capacity as a set of organisational processes and routines through which firms obtain, digest, transform and employ knowledge, to devise a dynamic organisational capability. Absorptive capacity is classified into four dimensions [31]: (1) acquisition, the ability to pinpoint, identify, assess and obtain operation-critical external knowledge; (2) assimilation, the comprehension of externally acquired knowledge; (3) transformation, the ability to merge old knowledge with newly acquired and assimilated knowledge; and (4) exploitation, the ability to incorporate the obtained, assimilated and transformed knowledge into usable organisational routines. According to Walter (2021) [17], capacity emphasises a focus on knowledge while OA maintains a focus on handling change; absorptive capacity is perpetual, while OA occurs only in response to changes in the environment. Previous literature confirms that the adoption of innovative practices in services or manufacturing requires a firm to be able to obtain, disseminate and employ external and internal knowledge. Innovation processes succeed through the imposing influence of leaders' skills and ability on accessing internal and external knowledge sources [32]. Absorptive capacity is a prerequisite for any knowledge-management activity that involves the deliberate management of knowledge flows beyond organisational limits, to generate innovations [33]. It indicates the presence of a knowledge base facilitating innovation adoption, where the setting is key to inspiring the joint generation of novel concepts and finding novel ways of utilising the external partner's knowledge. The absorptive capacity allows the company to actively collaborate in a pioneering manner, rather than passively observing. In the long term, absorptive capacity allows the consolidation of a high success rate in co-innovation projects, high credibility in virtual environments and a positive valuation by external partners, enhancing collaborative work [31, 32, 34].

\section{2-3- Transaction Cost Theory}

Transaction cost theory explains firms' innovation-adoption behaviours [35, 36], based on two behavioural assumptions: opportunism and bounded rationality. Bounded rationality means that humans are unlikely to have adequate capacity, information, time or resources to entertain every state-contingent outcome that a possible transaction entails, while opportunism means that humans will pursue their self-interest by making room for guile [37, 38]. In economics and related disciplines, transaction costs are economic-exchange costs, including search and information, bargaining and policing and enforcement costs [39]. Transaction cost theorists suggest classifying a firm's total incurred costs as transaction and production costs. Transaction/coordination costs are the costs of all the required information processing crucial to coordinating the work of primary people and machines, whereas production costs comprise costs incurred for the physical or other primary processes necessary to create and distribute products. When considering 'make-or-buy' sourcing decisions, decision-makers must weigh the production and transaction costs associated with executing a transaction within their firms, versus the costs of executing it in the market [39]. A transaction cost arises from an economic transaction conducted in a market [37, 40]. Agents have bounded rationality and maintain opportunistic behaviours to advance their interests above all; they have limited cognitive abilities and cannot entertain all possible events. Williamson $(1993,2008)[37,40]$ describes a transaction according to asset specificity, frequency and uncertainty. Asset specificity characterises a specialised investment that cannot be redeployed to alternatives or by alternative users without a productive-value loss. Asset frequency reduces transaction costs due to redeployable knowledge and standardised processes and contracts [41]. Asset uncertainty includes internal and external uncertainty. The first encompasses the complexity and tacit nature of the firm's internally performed tasks or that two different firms perform during a technological exchange. External uncertainty includes technological, fiscal and legal regulatory and competitive uncertainty [42].

\section{2-4- Conceptual Framework and Hypothesis Development}

The research framework for investigating factors affecting SME OI adoption was developed based on previous relevant literature on organisational agility and absorptive capacity concepts, in addition to transaction cost theory. This study's conceptual framework includes innovation performance since prior studies confirm it as a subsequent outcome of innovation adoption. Figure 1 illustrates the proposed research outline:

The hypotheses follow:

H1: Organisational agility significantly influences SME Open Innovation adoption.

H2: Economic and financial readiness significantly influences SME Open Innovation adoption.

H3: Absorptive capacity significantly influences SME Open Innovation adoption.

H4: Open Innovation adoption has a significantly positive effect on innovation performance.

H5: Open Innovation adoption mediates the effect of organisational agility on innovation performance.

H6: Open innovation adoption mediates the effect of absorptive capacity on innovation performance. 


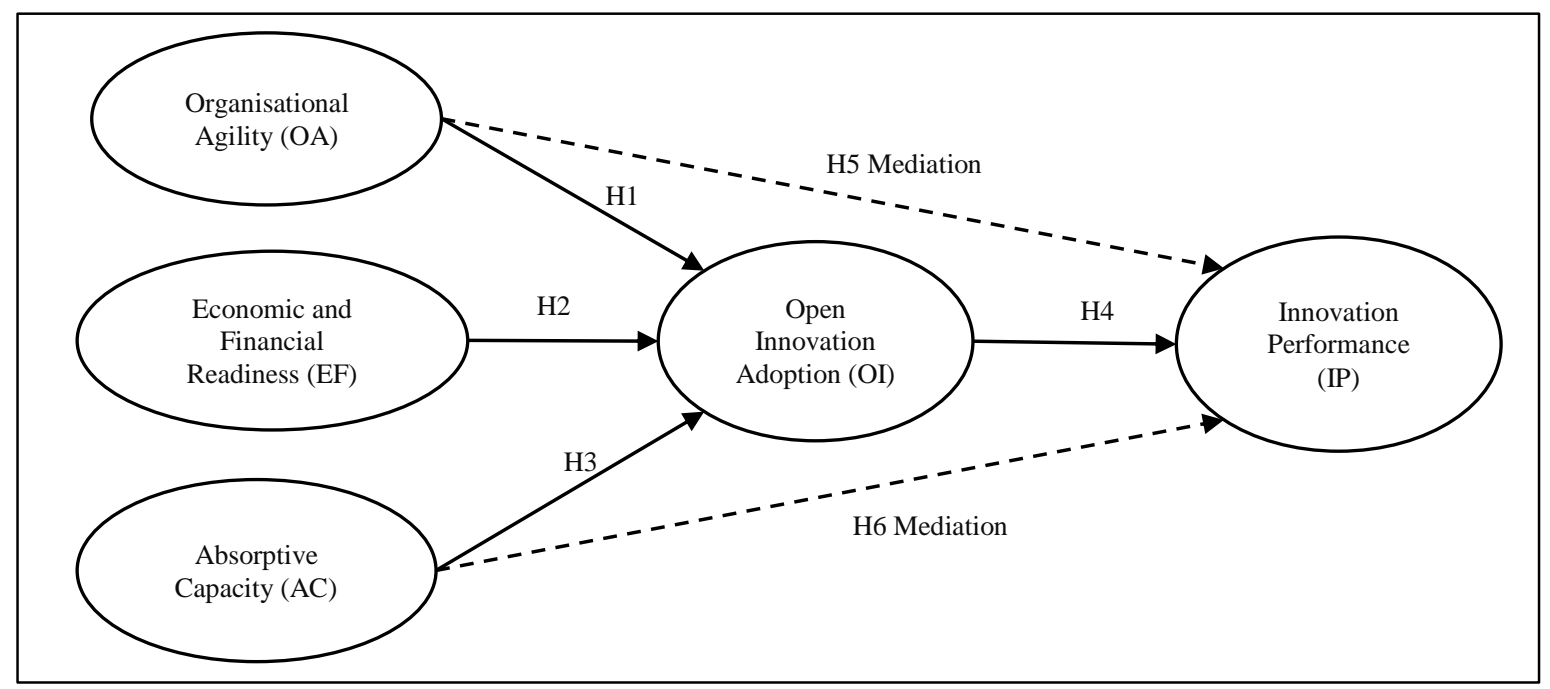

Figure 1. The proposed conceptual framework.

\section{3- Research Methodology}

\section{3-1- Research Design and Data Collection}

To expand the body of knowledge on open innovation and innovation performance in emerging-market countries, such as Thailand, a self-administered questionnaire with an explanatory cover letter was sent to Thai SME owners in three types of business: manufacturing, service and merchandising. The researcher acquired information on the studied firms from the database of the Department of Business Development, the Ministry of Commerce. Respondents remained anonymous. The study utilised a quantitative method to gauge the proposed research hypotheses and assess the suggested model. AMOS 22.0. SEM (Structural Equation Modelling) supported data evaluation. According to Anderson and Gerbing (1988) [43], the suggested sample size was at least 150 participants; however, other researchers [44] suggest at least 200 participants for SEM analysis or at least 5 cases per parameter for uncomplicated SEM. Since this study contained 28 observable variables, the minimum sample size was $28 \times 5=140$. Recipients returned a total of 249 questionnaires (approximately a 9\% response rate). Following the screening of the returned questionnaires, 214 useable questionnaires remained, exceeding the minimum sample size parameter and retained for further analysis. Figure 2 represents the research procedure.

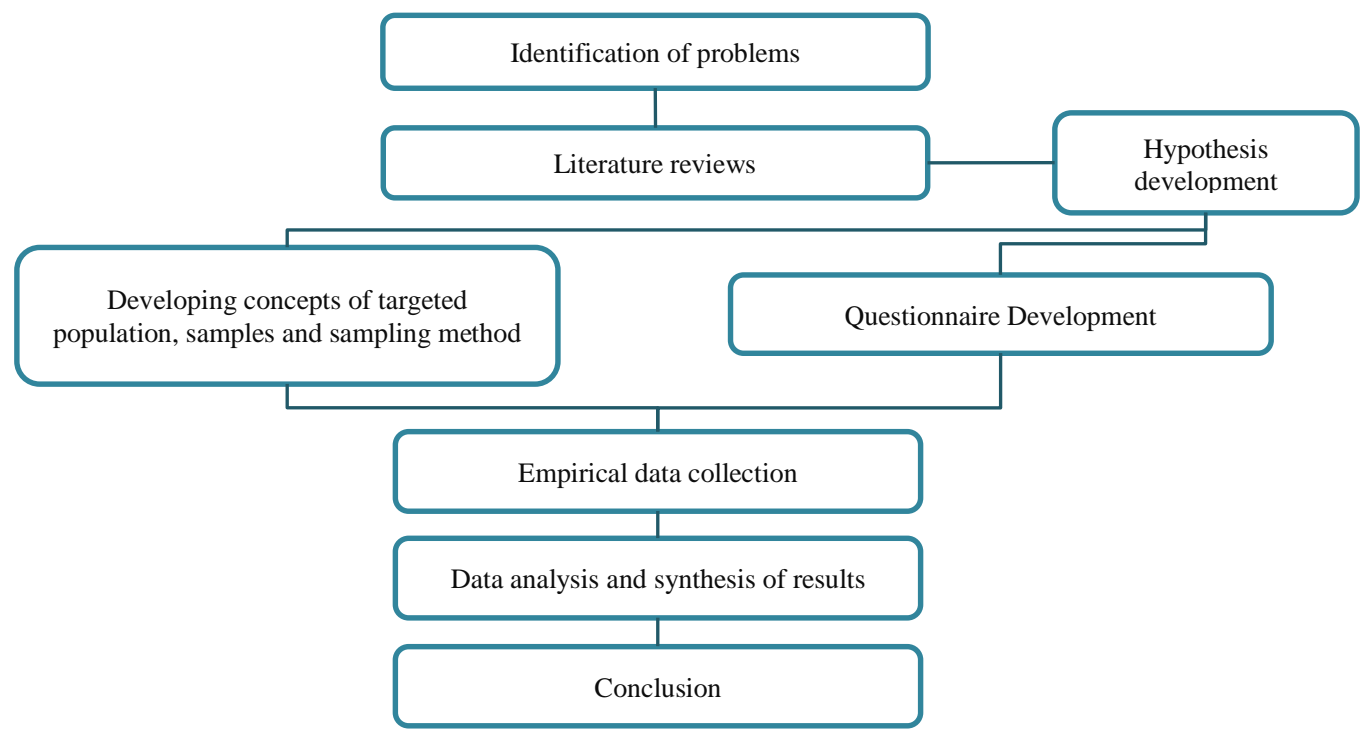

Figure 2. Flowchart of the research methodology.

\section{3-2- Questionnaire Development}

The questionnaires comprised two main sections: (1) typical information related to respondent demographics and (2) measurement items on a five-point Likert scale ranging from strongly agree (5) to strongly disagree (1).

This study gauges five constructs: Organisational Agility (OA), Economic and Financial Readiness (EF), Absorptive Capacity (AC), Open Innovation Adoption (OI) and Innovation Performance (IP). Organisational agility was a second- 
order construct with three subdimensions: Operational Agility (OPA), Customer Agility (CA) and Partnering Agility (PA). An eleven-item measure was modified from Felipe et al. (2017) [45]. To assess Economic and Financial Readiness, a five-item measure was modified from Oduro (2020) [46]. For Absorptive Capacity, a four-item measure was modified from [47]. Open Innovation Adoption was measured by four items adapted and modified from [46, 48], and Innovation Performance was measured by four items modified from Hameed et al. (2018) and Hoonsopon and Ruenrom (2012) $[48,49]$. Table 1 illustrates the constructs and measurement scales.

Table 1. Questionnaire constructs and variables.

\begin{tabular}{|c|c|c|}
\hline Constructs & Items & Observed Variables \\
\hline \multirow{3}{*}{$\begin{array}{l}\text { Operational Agility } \\
\text { (OPA) }\end{array}$} & OPA1 & $\begin{array}{l}\text { We fulfil demands for rapid response, special requests of our customers whenever such demands arise. Our } \\
\text { customers have confidence in our ability. }\end{array}$ \\
\hline & OPA2 & $\begin{array}{l}\text { We can quickly scale up or scale down our production/service levels to support fluctuations in demand } \\
\text { from the market. }\end{array}$ \\
\hline & OPA3 & $\begin{array}{l}\text { Whenever there is a disruption in supply from our suppliers, we can quickly make necessary alternative } \\
\text { arrangements and internal adjustments. }\end{array}$ \\
\hline \multirow{3}{*}{$\begin{array}{l}\text { Customer Agility } \\
\text { (CA) }\end{array}$} & CA1 & We are quick to make and implement appropriate decisions in the face of market/customer changes. \\
\hline & CA2 & We constantly look for ways to reinvent/reengineer our organisation to better serve our marketplace. \\
\hline & CA3 & We treat market-related changes and apparent chaos as opportunities to capitalise upon quickly. \\
\hline \multirow{5}{*}{$\begin{array}{l}\text { Partnering Agility } \\
\text { (PA) }\end{array}$} & PA1 & We collect detailed information about our suppliers and service providers. \\
\hline & PA2 & $\begin{array}{l}\text { We can exploit the resources and capabilities of suppliers to enhance the quality and quantity of products } \\
\text { and services. }\end{array}$ \\
\hline & PA3 & We work with external suppliers to create high-value products and services. \\
\hline & PA4 & We can manage relationships with outsourcing partners. \\
\hline & PA5 & We can switch suppliers to access lower costs, better quality or improved delivery times. \\
\hline \multirow{5}{*}{$\begin{array}{l}\text { Economic and } \\
\text { Financial Readiness } \\
\text { (EF) }\end{array}$} & EF1 & We have sufficient financial resources to undertake OI projects. \\
\hline & $\mathrm{EF} 2$ & $\begin{array}{l}\text { Our adequacy of state-of-the-art technologies, infrastructure and facilities encourages us to undertake } \\
\text { innovation projects with external actors. }\end{array}$ \\
\hline & EF3 & Our enterprise has the economic resources like land, labour and capital goods to embark on OI projects. \\
\hline & $\mathrm{EF}^{*}$ & The cost of securing and enforcing IP hinders our OI orientations. \\
\hline & $\mathrm{EF}^{*}$ & The cost of innovation impedes our adoption of the OI model. \\
\hline \multirow{4}{*}{$\begin{array}{l}\text { Absorptive } \\
\text { Capacity (AC) }\end{array}$} & $\mathrm{AC} 1$ & The search for relevant information concerning our industry is an everyday business in our company. \\
\hline & $\mathrm{AC} 2$ & $\begin{array}{l}\text { In our enterprise, there is a quick information flow. For example, if a business unit obtains important } \\
\text { information, it communicates this information promptly to all other business units or departments. }\end{array}$ \\
\hline & AC3 & $\begin{array}{l}\text { Our employees are used to absorbing new knowledge as well as preparing it for further purposes and } \\
\text { making it available. }\end{array}$ \\
\hline & AC4 & Our enterprise regularly reconsiders technologies and adapts them accordingly to new knowledge. \\
\hline \multirow{4}{*}{$\begin{array}{l}\text { Open Innovation } \\
\text { Adoption (OI) }\end{array}$} & OI1 & We adopt OI to improve our internal R\&D and innovation process. \\
\hline & $\mathrm{OI} 2$ & We use the OI to secure market share growth and global market reach. \\
\hline & $\mathrm{OI} 3$ & New ideas are always welcomed for open innovation in our enterprise. \\
\hline & OI4 & Engaging in OI is a good way to commercialise the idea. \\
\hline \multirow{4}{*}{$\begin{array}{l}\text { Innovation } \\
\text { Performance (IP) }\end{array}$} & IP1 & Our new product generates a competitive advantage for the company. \\
\hline & IP2 & Our new product is newer compared to the company's existing product. \\
\hline & IP3 & Our new product can respond to customers' needs. \\
\hline & IP4 & Compared to competitors within our sector, we exhibit a higher innovation performance. \\
\hline
\end{tabular}

Note: Organizational Agility (ORA) is the second construct of Operational Agility (OPA), Customer Agility (CA), Partnering Agility (PA); ${ }^{*}$ Reversed scoring item

\section{4- Results and Discussions}

\section{4-1- Descriptive Statistics Results}

The majority $(74.96 \%)$ of respondents were males. Most sampled enterprises were small-sized ( 5 employees) $(33.52 \%)$, operating in a service sector $(58.74 \%)$, with a company limited legal status (47.56\%). Prevalent years of operation and firm capital were 2-5 years (34.63\%) and1-10 million Baht (32.79\%), respectively. 
Table 2. Descriptive statistics.

\begin{tabular}{|c|c|c|c|}
\hline Item & Description & Sample & $(\%)$ \\
\hline \multirow{2}{*}{ Gender } & Male & 160 & 74.96 \\
\hline & Female & 54 & 25.04 \\
\hline \multirow{4}{*}{ Years of Operation } & Less than 1 & 63 & 29.45 \\
\hline & $2-5$ & 74 & 34.63 \\
\hline & $6-10$ & 56 & 25.96 \\
\hline & Above 10 & 21 & 9.96 \\
\hline \multirow{4}{*}{ Legal Status } & Sole proprietorship & 75 & 35.12 \\
\hline & Partnership & 34 & 15.96 \\
\hline & Company Limited & 102 & 47.56 \\
\hline & Others & 3 & 1.36 \\
\hline \multirow{3}{*}{ Sector of Operation } & Manufacturing & 33 & 15.63 \\
\hline & Service & 126 & 58.74 \\
\hline & Merchandising & 55 & 25.63 \\
\hline \multirow{4}{*}{ Number of Employees } & Less than 5 & 72 & 33.52 \\
\hline & $5-25$ & 45 & 20.89 \\
\hline & $26-50$ & 34 & 15.96 \\
\hline & More than 50 & 63 & 29.63 \\
\hline \multirow{5}{*}{$\begin{array}{l}\text { Firm Capital } \\
\text { (Million Baht) }\end{array}$} & Less than 1 & 64 & 29.86 \\
\hline & $1-10$ & 70 & 32.79 \\
\hline & $11-50$ & 37 & 17.23 \\
\hline & $51-200$ & 33 & 15.56 \\
\hline & More than 200 & 10 & 4.56 \\
\hline
\end{tabular}

Note: $\mathrm{N}=214$; missing data are not shown in the table; $1 \mathrm{USD}=30.12 \mathrm{Baht}$

\section{4-2- Measurement Model}

For hypothesis testing, the authors used Confirmatory Factor Analysis, following Hair et al. (2010) [50] by defining a construct's validity as a threshold at which the observed variables correspond to latent variables designed to be gauged theoretically. Accordingly, the authors assessed convergent and discriminant validities, with the results confirming the number of items for each construct as follows: OPA (3 items), CA (3 items), PA (5 items), EF (5 items), AC (4 items), OI (4 items) and IP (4 items). Cronbach's Alpha was measured in the range of 0.776-0.944. Tables 3 and 4 summarise the results for the measurement model:

Table 3. The factor loadings, Composite Reliability (CR), Average Variance Extracted (AVE) and Cronbach's alpha.

\begin{tabular}{|c|c|c|c|c|c|}
\hline Construct & Item Code & Item Loadings & CR & AVE & Cronbach's Alpha \\
\hline \multirow{3}{*}{ Organisational Agility (OA) } & OPA & 0.756 & \multirow{3}{*}{0.791} & \multirow{3}{*}{0.557} & \multirow{3}{*}{0.870} \\
\hline & $\mathrm{CA}$ & $0.755^{* * *}$ & & & \\
\hline & PA & $0.728^{* * *}$ & & & \\
\hline \multirow{3}{*}{ Operational Agility (OPA) } & OPA1 & 0.788 & \multirow{3}{*}{0.836} & \multirow{3}{*}{0.631} & \multirow{3}{*}{0.832} \\
\hline & OPA2 & $0.877^{* * *}$ & & & \\
\hline & OPA3 & $0.710^{* * *}$ & & & \\
\hline \multirow{3}{*}{ Customer Agility (CA) } & CA1 & 0.684 & \multirow{3}{*}{0.778} & \multirow{3}{*}{0.539} & \multirow{3}{*}{0.776} \\
\hline & CA2 & $0.762^{* * *}$ & & & \\
\hline & CA3 & $0.754^{* * * *}$ & & & \\
\hline \multirow{5}{*}{ Partnering Agility (PA) } & PA1 & 0.864 & \multirow{5}{*}{0.935} & \multirow{5}{*}{0.741} & \multirow{5}{*}{0.933} \\
\hline & PA2 & $0.873^{* * *}$ & & & \\
\hline & PA3 & $0.905^{\text {*** }}$ & & & \\
\hline & PA4 & $0.851^{* * *}$ & & & \\
\hline & PA5 & $0.808^{* * *}$ & & & \\
\hline
\end{tabular}




\begin{tabular}{|c|c|c|c|c|c|}
\hline \multirow{5}{*}{ Economic and Financial Readiness (EF) } & EF1 & 0.828 & \multirow{5}{*}{0.944} & \multirow{5}{*}{0.771} & \multirow{5}{*}{0.944} \\
\hline & EF2 & $0.934^{* * *}$ & & & \\
\hline & EF3 & $0.920^{* * *}$ & & & \\
\hline & EF4 & $0.891^{\text {**** }}$ & & & \\
\hline & EF5 & $0.810^{* * * *}$ & & & \\
\hline \multirow{4}{*}{ Absorptive Capacity (AC) } & $\mathrm{AC} 1$ & 0.879 & \multirow{4}{*}{0.911} & \multirow{4}{*}{0.721} & \multirow{4}{*}{0.909} \\
\hline & $\mathrm{AC} 2$ & $0.871^{* * *}$ & & & \\
\hline & $\mathrm{AC} 3$ & $0.873^{\text {**** }}$ & & & \\
\hline & $\mathrm{AC} 4$ & $0.768^{* * *}$ & & & \\
\hline \multirow{4}{*}{ Open Innovation Adoption (OI) } & OI1 & 0.760 & \multirow{4}{*}{0.850} & \multirow{4}{*}{0.586} & \multirow{4}{*}{0.847} \\
\hline & OI2 & $0.768^{* * * *}$ & & & \\
\hline & $\mathrm{OI} 3$ & $0.751^{* * *}$ & & & \\
\hline & OI4 & $0.782^{* * *}$ & & & \\
\hline \multirow{4}{*}{ Innovation Performance (IP) } & IP1 & 0.722 & \multirow{4}{*}{0.883} & \multirow{4}{*}{0.656} & \multirow{4}{*}{0.874} \\
\hline & IP2 & $0.904^{* * *}$ & & & \\
\hline & IP3 & $0.884^{* * *}$ & & & \\
\hline & IP4 & $0.710^{* * *}$ & & & \\
\hline
\end{tabular}

Notes: OA is the second order construct of OPA, CA and PA; OPA, OPA1, CA1, PA1, EF1, AC1, OI1 and IP1 are fixed parameters; *p < 0.05; ** $<0.01$; $* * * \mathrm{p}<0.001$. Fit indices: Chi-square $=584.509 ; \mathrm{df}=337 ; \mathrm{CMIN} / \mathrm{df}=1.734 ; \mathrm{GFI}=0.903 ; \mathrm{CFI}=0.967 ; \mathrm{TLI}=0.963 ; \mathrm{IFI}=0.967 ; \mathrm{RMSEA}=0.044$

Table 4. Discriminant validity.

\begin{tabular}{|c|c|c|c|c|c|}
\hline & OA & EF & AC & OI & IP \\
\hline OA & $\mathbf{0 . 7 4 6}$ & & & & \\
\hline EF & 0.462 & $\mathbf{0 . 8 7 8}$ & & & \\
\hline AC & 0.593 & 0.495 & $\mathbf{0 . 8 4 9}$ & & \\
\hline OI & 0.497 & 0.571 & 0.524 & $\mathbf{0 . 7 6 6}$ & \\
\hline IP & 0.351 & 0.535 & 0.388 & 0.522 & $\mathbf{0 . 8 1 0}$ \\
\hline
\end{tabular}

Notes: The diagonal elements in bold in the table denote the AVE square root for every construct used in the study. Nondiagonal elements denote correlations between constructs.

As Table 3 shows, analysis of measurements with seven constructs attains a satisfactory model fit (Chi-square $=$ 584.509; $\mathrm{df}=337 ; \mathrm{CMIN} / \mathrm{df}=1.734 ; \mathrm{GFI}=0.903 ; \mathrm{CFI}=0.967 ; \mathrm{TLI}=0.963 ; \mathrm{IFI}=0.967 ; \mathrm{RMSEA}=0.044)$. Convergent validity is indicated by item loadings (standardised estimates), Average Variance Extracted (AVE) and Composite Reliability (CR). These measures attained the values suggested by Hair et al. (2010) [50], i.e., AVE > 0.5 and CR > 0.7. This indicates acceptance of convergent validity. Table 5 indicates that the discriminant validity test was performed. The study attained discriminant validity because every construct's AVE square root was higher than the respective interconstruct correlation estimates.

\section{4-3- Structural Model and Hypotheses Testing}

After assessing the measurement model, the structural model was developed. Figure 3 demonstrates outcomes for the path model, illustrating an adequate model fit to the data.

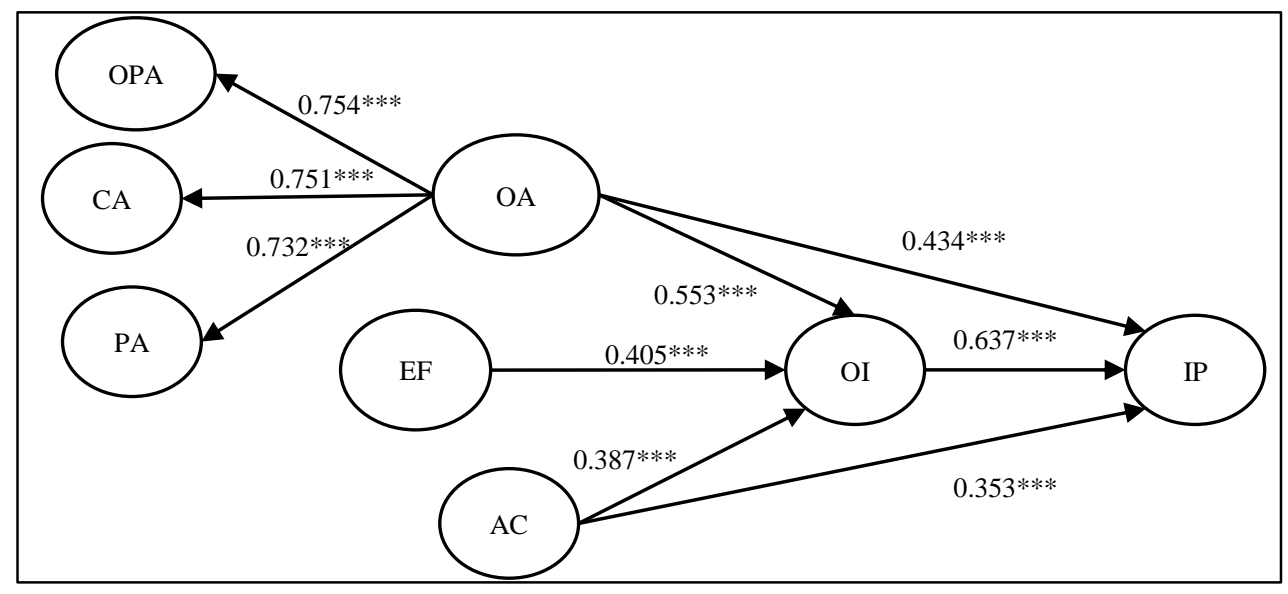

Figure 3. SEM result.

Notes: ${ }^{*} \mathrm{p}<0.05 ; * * \mathrm{p}<0.01 ; * * \mathrm{p}<0.001$. Fit indices: Chi-square $=596.946 ; \mathrm{df}=340 ; \mathrm{CMIN} / \mathrm{df}=1.756 ; \mathrm{GFI}=0.901 ; \mathrm{CFI}=0.966 ;$ TLI $=0.962 ; \mathrm{IFI}=0.966 ; \mathrm{RMSEA}$ $=0.044$. 
Table 5. Structural parameter estimates.

\begin{tabular}{cccc}
\hline Hypotheses & Relationship & Estimate $) \mathbf{b}($ & Result \\
\hline H1 & OA $\rightarrow$ OI & $0.553^{* * *}$ & Supported \\
H2 & EF $\rightarrow$ OI & $0.405^{* * *}$ & Supported \\
H3 & AC $\rightarrow$ OI & $0.387^{* *}$ & Supported \\
H4 & OI $\rightarrow$ IP & $0.637^{* * *}$ & Supported \\
\hline
\end{tabular}

Notes: $\mathrm{R}^{2}($ Open innovation adoption $)=0.445 ; \mathrm{R}^{2}$ (Innovation performance $)=0.544 ; *^{\mathrm{p}}<0.05 ; * * \mathrm{p}<0.01 ; * * \mathrm{p}<0.001$

The hypothesised path model outcomes indicate an adequate model fit to the data (Chi-square $=596.946 ; \mathrm{df}=340$; $\mathrm{CMIN} / \mathrm{df}=1.756 ; \mathrm{GFI}=0.901 ; \mathrm{CFI}=0.966 ; \mathrm{TLI}=0.962 ; \mathrm{IFI}=0.966 ; \mathrm{RMSEA}=0.044)$. Table 6 shows the results for the hypothesis testing, which indicate significance in the four hypotheses' relationships. Specifically, the outcomes supported the hypotheses concerning the relationship between OA and OI $(\mathrm{H} 1: \mathrm{b}=0.553$, $\mathrm{t}$-value $=8.134$, sig $<0.001)$, between $\mathrm{EF}$ and $\mathrm{OI}(\mathrm{H} 2: \mathrm{b}=0.405$, $\mathrm{t}$-value $=6.873$, sig < 0.001) and between $\mathrm{AC}$ and $\mathrm{OI}(\mathrm{H} 3: \mathrm{b}=0.387, \mathrm{t}$-value $=$ 4.242, sig < 0.001). Meanwhile, supporting H4, OI positively impacted IP (H4: $b=0.637$, t-value $=11.253$, sig < 0.001$)$.

A bootstrapping technique tested the Organisational Agility mediating effect on Innovation Performance through Open Innovation Adoption. The result of the mediation analysis with bootstrapping illustrated that Organisational Agility directly impacted Innovation Performance (0.434; $\mathrm{p}<0.001 ; 95 \%$ CI [0.198, 0.502]), and Innovation Performance through Open Innovation Adoption had a considerable indirect impact $(0.352 ; \mathrm{p}<0.001 ; 95 \%$ CI $[0.167$, 0.401]), confirming partial mediation. The mediation analysis of Absorptive Capacity's mediating effect also confirmed that Open Innovation Adoption partially mediates the effect of Absorptive Capacity on Innovation Performance $(\mathrm{DE}=$ $0.353 ; \mathrm{p}<0.001 ; 95 \%$ CI $[0.171,0.418])(\mathrm{IE}=0.247 ; \mathrm{p}<0.001 ; 95 \%$ CI $[0.168,0.354])$. The mediation effect results support H5 and H6. Table 6 illustrates the results of mediation analysis with bootstrapping.

Table 6. The mediation analysis results.

\begin{tabular}{lcrc}
\hline \multicolumn{1}{c}{ Hypothesis } & Direct Effect & Indirect Effect & Result \\
\hline $\begin{array}{l}\text { H5: Open innovation adoption mediates the effect of organisational } \\
\text { agility on innovation performance. }\end{array}$ & $0.434(* * *)$ & $0.352(* * *)$ \\
$\begin{array}{l}\text { H6: Open innovation adoption mediates the effect of absorptive } \\
\text { capacity on innovation performance. }\end{array}$ & $0.353(* * *)$ & $0.247(* * *)$ & Partial Mediation \\
\hline
\end{tabular}

Note: $* * * \mathrm{p}<0.001$

The results of structural equation modelling analysis provide more insight into antecedents of SMEs' open innovation adoption and the consequent innovation performance. Our results confirm prior studies the World Bank (2018) and Lichtenthaler (2008) [5, 10], namely, numerous elements, both explicit and implicit factors, affect firms' innovation adoptions and practices. Our proposed framework is one of a few studies of integrated firms' implicit capabilities - OA and $\mathrm{AC}$ with $\mathrm{EF}$ - to explain open innovation adoption in an SME context. Based on the path-analysis results, OA had the greatest influence on open innovation adoption. This finding is in the line with Fabian (2019) [51], i.e. fostering firms' innovation adoptions and practices can occur through enhancing organisational agility, leading to the firm's achieving better flexibility, increased speed and enhanced customer focus, which subsequently impact the firm's OI adoption and increase its innovation capacity, improving the effectiveness of innovation performance Fabian (2019) [51]. Considering subdimensions of OA based on the measurement model analysis results, operational agility emerged as the most important determinant of OA. That is, SMEs' ability to modify and adapt their operations and technology to constantly evolving business requirements is the critical element for fostering OI adoption in emerging markets. Customer agility, the second important determinant of OA, refers to the firm's ability to sense and respond quickly to customer-based opportunities for innovation and competitive action. Customer agility also involves leveraging big data to understand customer needs. Modern marketing techniques and practices, such as neuromarketing [52], can provide an innovative method for gaining customer insight, helping firms to achieve this form of OA.

Partnering agility is a significant form of OA influencing OI adoption. SME owners should circumspectly consider the firm's ability to leverage the assets, knowledge and competencies of such stakeholders as suppliers, distributors, contract manufacturers and logistic providers [53] as one of the critical key success factors for attaining open innovation adoptions and practices. SMEs can start using innovation intermediaries in their search for innovation partners. SEM results show economic and financial readiness as the third most important factor affecting SMEs' OI adoption. This finding was consistent with Oduro's (2020) [46] that to a large extent, firms' ability to undertake innovation projects depends on their financial and economic resources. SMEs should consider exploiting newly emerging financial technologies, such as fintech solutions and financial crowdsourcing, to fill an economic and financial-readiness gap. Moreover, designing an appropriate regulatory environment for supporting OI adoptions and practices is one of a government's most critical national-agenda items. A firm's ability to acquire, disseminate and utilise internal and external knowledge can function as absorptive capacity. Our finding confirmed previous findings of Aboelmaged and 
Hashem (2019) [32] that absorptive capacity positively influences innovation adoption in SMEs. SME owners should stimulate knowledge transfer within a firm and consider employing qualified human resources. Furthermore, SMEs should emphasise exploratory, assimilative, transformative and exploitative learning processes equally. Nurturing learning organisational culture within a firm-e.g. setting up a support network of trainees to encourage exchanges of their learning experiences, supporting employees in applying the knowledge and skills learned in training at work and allowing them to make mistakes in practice-will enhance a firm's absorptive capacity, consequently influencing SMEs open innovation adoption and innovation performance.

\section{5- Conclusion}

OI is an imperative firm approach to implementing innovation initiatives. This study explores antecedents of OI adoption and innovation performance among SMEs in emerging economies. As the most frequently occurring enterprises in those economies, SMEs are insufficiently studied in the OI literature [54]. Accordingly, a holistic conceptual framework based on concepts of organisational agility, absorptive capacity and transaction cost theory was proposed for an investigation of factors influencing SMEs' OI adoption. The results showed that organisational agility, economic and financial readiness and absorptive capacity play significant roles in SME adoption of OI. These findings align with identifying absorptive capacity as a prerequisite for co-innovation [31]. Also, these results extend the existing body of knowledge on the correlation between organisation agility and OI [26]. Organisational agility benefits businesses by identifying and adapting to market changes. Agile organisations maintain a solid market knowledge base and responsiveness to current market trends. Organisational agility entails a firm's inclination towards OI adoption. Economic and financial readiness is also a driving factor, aligning with the realisation that an economic and financial issue determines the degree of OI adoption in the SME context [46].

This study also concerns SME owners and policy-makers. First, to effectively implement an OI approach in an organisation, entrepreneurs and SME leaders must cultivate an organisational-agility culture for all employees. Furthermore, nurturing the organisation's absorptive capacity is also essential for SMEs to successfully maintain an OI approach. Being knowledge-intensive and developing capacities to obtain and assimilate internal and external knowledge are also such imperative initiatives for achieving an OI orientation. Information sharing and collaborative rewards develop the absorptive capacity that subsequently entails the firm's ability to successfully adopt an OI approach. Second, to promote OI in society, policy-makers and national innovation agencies should support SMEs gaining organisational agility and absorptive-capacity knowledge. For example, providing training courses for entrepreneurs and SMEs' leaders to better understand and implement organisational agility and absorptive capacity culture in their enterprises should be a national agenda item for SME development in emerging economies. Our study also generates awareness of the necessity of absorptive capacity and shows that practitioners should nurture its development [47]. Our research indicates the beneficial relationship of organisational agility, economic and financial reediness, absorptive capacity, OI adoption and firms' innovation performance. SMEs can benefit from open innovation as it inspires the growth of their knowledge base, rendering them more innovative.

\section{5-1-Limitations and Future Research}

This study contains some limitations. First, the results come from a sample of SMEs in Thailand, signalling the need to consider the generalisability of the findings to SMEs in other emerging-economy countries. Second, a self-reported questionnaire was this study's research tool, so respondents may not have answered truthfully or may have provided invalid answers. In the future, a mixed-methods approach could provide deeper insight into factors affecting and driving SME OI adoption in emerging economies. Future research should expand boundaries to comparatively investigate factors influencing OI adoption between large enterprises and SMEs, to better understand and expand our body of knowledge on enhancing nations' innovation capability and achieving higher economic growth towards an innovationdriven economy. The factors this study highlights could serve as a good basis for further exploration of cultivating SME OI adoptions and practices. Future research may capture the dynamics of research variables over time, using longitudinal studies or qualitative research methods.

\section{6- Declarations}

\section{6-1-Author Contributions}

W.P. conceptualized and participated study design, coordinated data collection, carried out the initial analyses, drafted the initial manuscript, and read and approved the manuscript. S.T. participated in study design, guided the methodology coordinated and supervised data collection and analyses, reviewed and edited manuscript. Both authors read and approved the manuscript as submitted and agree to be accountable for all aspects of the work.

\section{6-2-Data Availability Statement}

Due to the nature of this research, participants of this study did not agree for their data to be shared publicly, so supporting data is not available. 


\section{6-3-Funding}

The authors received no financial support for the research, authorship, and/or publication of this article.

\section{6-4- Conflicts of Interest}

The authors declare that there is no conflict of interests regarding the publication of this manuscript. In addition, the ethical issues, including plagiarism, informed consent, misconduct, data fabrication and/or falsification, double publication and/or submission, and redundancies have been completely observed by the authors.

\section{7- References}

[1] Rasheed, Muhammad Athar, Khuram Shahzad, and Sajid Nadeem. "Transformational Leadership and Employee Voice for Product and Process Innovation in SMEs.” Innovation \& Management Review 18, no. 1 (March 11, 2021): 69-89. doi:10.1108/inmr-01-2020-0007.

[2] Indrawati, Henny, Caska, and Suarman. "Barriers to Technological Innovations of SMEs: How to Solve Them?" International Journal of Innovation Science 12, no. 5 (November 30, 2020): 545-564. doi:10.1108/ijis-04-2020-0049.

[3] Wong, Poh Kam, Yuen Ping Ho, and Erkko Autio. "Entrepreneurship, Innovation and Economic Growth: Evidence from GEM Data." Small Business Economics 24, no. 3 (April 2005): 335-350. doi:10.1007/s11187-005-2000-1.

[4] Didonet, Simone, and Guillermo Diaz-Villavicencio. "Innovation Management in Market-Oriented SMEs: Learning and Internal Arrangements for Innovation.” International Journal of Organizational Analysis 28, no. 5 (April 21, 2020): $985-1003$. doi:10.1108/ijoa-09-2019-1885.

[5] World Bank. "Small and Medium Enterprises (SMEs) Finance. Improving SMEs' Access to Finance and Finding Innovative Solutions to Unlock Sources of Capital." (2018). Available online: https://www.worldbank.org/en/topic/smefinance (accessed on March 2021).

[6] Crema, Maria, Chiara Verbano, and Karen Venturini. "Linking Strategy with Open Innovation and Performance in SMEs." Measuring Business Excellence 18, no. 2 (May 13, 2014): 14-27. doi:10.1108/mbe-07-2013-0042.

[7] Chesbrough, Henry William. Open innovation: The new imperative for creating and profiting from technology. Harvard Business Press, 2003. Available online: https://www.nmit.edu.my/wp-content/uploads/2017/10/Open-Innovation-the-New-Imperative-forCreating-and-Profiting-from-Technology.pdf (accessed on March 2021).

[8] Christensen, Jens Frøslev. "Wither core competency for the large corporation in an open innovation world." Open innovation: Researching a new paradigm 35 (2006): 35-61.

[9] Chesbrough, Henry W., and Melissa M. Appleyard. “Open Innovation and Strategy.” California Management Review 50, no. 1 (October 2007): 57-76. doi:10.2307/41166416.

[10] Lichtenthaler, Ulrich. “Open Innovation in Practice: An Analysis of Strategic Approaches to Technology Transactions." IEEE Transactions on Engineering Management 55, no. 1 (February 2008): 148-157. doi:10.1109/tem.2007.912932.

[11] Brunswicker, Sabine, and Vareska Van de Vrande. "Exploring open innovation in small and medium-sized enterprises." New Frontiers in Open Innovation 1 (2014): 135-156.

[12] Lee, Sungjoo, Gwangman Park, Byungun Yoon, and Jinwoo Park. "Open Innovation in SMEs—An Intermediated Network Model.” Research Policy 39, no. 2 (March 2010): 290-300. doi:10.1016/j.respol.2009.12.009.

[13] Spithoven, André, Wim Vanhaverbeke, and Nadine Roijakkers. "Open Innovation Practices in SMEs and Large Enterprises." Small Business Economics 41, no. 3 (October 20, 2012): 537-562. doi:10.1007/s11187-012-9453-9.

[14] Radziwon, Agnieszka, and Marcel Bogers. "Open Innovation in SMEs: Exploring Inter-Organizational Relationships in an Ecosystem.” Technological Forecasting and Social Change 146 (September 2019): 573-587. doi:10.1016/j.techfore.2018.04.021.

[15] Hungund, Sumukh, and Venkatesh Mani. "Benchmarking of Factors Influencing Adoption of Innovation in Software Product SMEs: An empirical evidence from India.” Benchmarking: An International Journal 26, no. 5 (February 13, 2019): 1451-1468. doi:10.1108/bij-05-2018-0127.

[16] Cai, Zhao, Hefu Liu, Qian Huang, and Liang Liang. "Developing Organizational Agility in Product Innovation: The Roles of IT Capability, KM Capability, and Innovative Climate.” R\&D Management 49, no. 4 (December 22, 2017): $421-438$. doi:10.1111/radm.12305.

[17] Walter, Anna-Theresa. "Organizational Agility: Ill-Defined and Somewhat Confusing? A Systematic Literature Review and Conceptualization.” Management Review Quarterly 71, no. 2 (April 19, 2020): 343-391. doi:10.1007/s11301-020-00186-6.

[18] Lu, and K. (Ram) Ramamurthy. "Understanding the Link between Information Technology Capability and Organizational Agility: An Empirical Examination.” MIS Quarterly 35, no. 4 (2011): 931-954. doi:10.2307/41409967. 
[19] Bessant, John, David Francis, Sandie Meredith, Raphael Kaplinsky, and Steve Brown. "Developing Manufacturing Agility in SMEs." International Journal of Manufacturing Technology and Management 2, no. 1-7 (2000): 730-756. doi:10.1504/ijmtm.2000.001374.

[20] Vázquez-Bustelo, Daniel, Lucía Avella, and Esteban Fernández. “Agility Drivers, Enablers and Outcomes.” International Journal of Operations \& Production Management 27, no. 12 (November 13, 2007): 1303-1332. doi:10.1108/01443570710835633.

[21] Zandi, Faramak, and Madjid Tavana. "A Fuzzy Group Quality Function Deployment Model for e-CRM Framework Assessment in Agile Manufacturing.” Computers \& Industrial Engineering 61, no. 1 (August 2011): 1-19. doi:10.1016/j.cie.2011.02.004.

[22] Sambamurthy, Bharadwaj, and Grover. "Shaping Agility through Digital Options: Reconceptualizing the Role of Information Technology in Contemporary Firms.” MIS Quarterly 27, no. 2 (2003): 237-263. doi:10.2307/30036530.

[23] Chakravarty, Anindita, Rajdeep Grewal, and V. Sambamurthy. "Information Technology Competencies, Organizational Agility, and Firm Performance: Enabling and Facilitating Roles.” Information Systems Research 24, no. 4 (December 2013): $976-997$. doi:10.1287/isre.2013.0500.

[24] Pavlou, Paul A., and Omar A. El Sawy. “Understanding the Elusive Black Box of Dynamic Capabilities.” Decision Sciences 42, no. 1 (February 2011): 239-273. doi:10.1111/j.1540-5915.2010.00287.x.

[25] Teece, David, Margaret Peteraf, and Sohvi Leih. "Dynamic Capabilities and Organizational Agility: Risk, Uncertainty, and Strategy in the Innovation Economy." California Management Review 58, no. 4 (August 2016): 13-35. doi:10.1525/cmr.2016.58.4.13.

[26] Liao, Suqin, Zhiying Liu, and Chaoliang Ma. "Direct and Configurational Paths of Open Innovation and Organisational Agility to Business Model Innovation in SMEs.” Technology Analysis \& Strategic Management 31, no. 10 (March 31, 2019): 12131228. doi:10.1080/09537325.2019.1601693.

[27] Scuotto, Veronica, Gabriele Santoro, Stefano Bresciani, and Manlio Del Giudice. "Shifting Intra- and Inter-Organizational Innovation Processes towards Digital Business: An Empirical Analysis of SMEs.” Creativity and Innovation Management 26, no. 3 (August 16, 2017): 247-255. doi:10.1111/caim.12221.

[28] Hu, Yansong, Peter McNamara, and Damien McLoughlin. “Outbound Open Innovation in Bio-Pharmaceutical Out-Licensing.” Technovation 35 (January 2015): 46-58. doi:10.1016/j.technovation.2014.07.004.

[29] Mikalef, Patrick, and Adamantia Pateli. "Information Technology-Enabled Dynamic Capabilities and Their Indirect Effect on Competitive Performance: Findings from PLS-SEM and fsQCA.” Journal of Business Research 70 (January 2017): 1-16. doi:10.1016/j.jbusres.2016.09.004.

[30] Overby, Eric, Anandhi Bharadwaj, and V Sambamurthy. "Enterprise Agility and the Enabling Role of Information Technology." European Journal of Information Systems 15, no. 2 (April 2006): 120-131. doi:10.1057/palgrave.ejis.3000600.

[31] Arias-Pérez, José, Nelson Lozada, and Edwin Henao-García. "When It Comes to the Impact of Absorptive Capacity on CoInnovation, How Really Harmful Is Knowledge Leakage?” Journal of Knowledge Management 24, no. 8 (July 13, 2020): 18411857. doi:10.1108/jkm-02-2020-0084.

[32] Aboelmaged, Mohamed, and Gharib Hashem. "Absorptive Capacity and Green Innovation Adoption in SMEs: The Mediating Effects of Sustainable Organisational Capabilities.” Journal of Cleaner Production 220 (May 2019): 853-863. doi:10.1016/j.jclepro.2019.02.150.

[33] Spithoven, André, Bart Clarysse, and Mirjam Knockaert. "Building Absorptive Capacity to Organise Inbound Open Innovation in Traditional Industries.” Technovation 30, no. 2 (February 2010): 130-141. doi:10.1016/j.technovation.2009.08.004.

[34] Tsou, Hung-Tai, Ja-Shen Chen, and Ya-Wen (Diana) Yu. "Antecedents of Co-Development and Its Effect on Innovation Performance.” Management Decision 57, no. 7 (July 8, 2019): 1609-1637. doi:10.1108/md-04-2018-0421.

[35] Wang, Yi-Shun, Shun-Cheng Wu, Hsin-Hui Lin, Yu-Min Wang, and Ting-Rong He. "Determinants of user adoption of web"Automatic Teller Machines': an integrated model of'Transaction Cost Theory'and'Innovation Diffusion Theory'." The Service Industries Journal 32, no. 9 (2012): 1505-1525. doi:10.1080/02642069.2010.531271.

[36] Hsieh, Ching-Tang, Hao-Chen Huang, and Wei-Long Lee. "Using Transaction Cost Economics to Explain Open Innovation in Start-Ups.” Management Decision 54, no. 9 (October 17, 2016): 2133-2156. doi:10.1108/md-01-2016-0012.

[37] Williamson, Oliver E. "Transaction Cost Economics." Handbook of New Institutional Economics (2008): 41-65. doi:10.1007/978-3-540-69305-5_4.

[38] Aboelmaged, Mohamed. "The Drivers of Sustainable Manufacturing Practices in Egyptian SMEs and Their Impact on Competitive Capabilities: A PLS-SEM Model.” Journal of Cleaner Production 175 (February 2018): $207-221$. doi:10.1016/j.jclepro.2017.12.053.

[39] Lacity, Mary C., Leslie P. Willcocks, and Shaji Khan. "Transaction Cost Economics and After: Addressing the New Theory Challenge.” The New IT Outsourcing Landscape (2012): 89-126. doi:10.1057/9781137012296_3. 
[40] Williamson, Oliver E. “Transaction Cost Economics and Organization Theory.” Industrial and Corporate Change 2, no. 2 (1993): 107-156. doi:10.1093/icc/2.2.107.

[41] Rørstad, Per Kristian, Arild Vatn, and Valborg Kvakkestad. "Why Do Transaction Costs of Agricultural Policies Vary?" Agricultural Economics 36, no. 1 (January 2007): 1-11. doi:10.1111/j.1574-0862.2007.00172.x.

[42] Chedrawi, Charbel, Bissane Harb, and Mariam Saleh. "The E-Banking and the Adoption of Innovations from the Perspective of the Transactions Cost Theory: Case of the Largest Commercial Banks in Lebanon.” ICT for a Better Life and a Better World (2019): 149-164. doi:10.1007/978-3-030-10737-6_10.

[43] Anderson, James C., and David W. Gerbing. "Structural Equation Modeling in Practice: A Review and Recommended TwoStep Approach.” Psychological Bulletin 103, no. 3 (May 1988): 411-423. doi:10.1037/0033-2909.103.3.411.

[44] Kline, Rex B. "Principles and practice of structural equation modeling (3. Bask1)." New York, NY: Guilford (2011).

[45] Felipe, Carmen M., José L. Roldán, and Antonio L. Leal-Rodríguez. "Impact of Organizational Culture Values on Organizational Agility.” Sustainability 9, no. 12 (December 17, 2017): 2354. doi:10.3390/su9122354.

[46] Oduro, Stephen. "Exploring the Barriers to SMEs' Open Innovation Adoption in Ghana.” International Journal of Innovation Science 12, no. 1 (February 3, 2020): 21-51. doi:10.1108/ijis-11-2018-0119.

[47] Flatten, Tessa Christina, Greta Isabell Greve, and Malte Brettel. "Absorptive Capacity and Firm Performance in SMEs: The Mediating Influence of Strategic Alliances.” European Management Review 8, no. 3 (September 2011): 137-152. doi:10.1111/j.1740-4762.2011.01015.x.

[48] Hameed, Waseem U1, Muhammad Farhan Basheer, Jawad Iqbal, Ayesha Anwar, and Hafiz Khalil Ahmad. "Determinants of Firm's Open Innovation Performance and the Role of R \& D Department: An Empirical Evidence from Malaysian SME's." Journal of Global Entrepreneurship Research 8, no. 1 (October 5, 2018): 1-20. doi:10.1186/s40497-018-0112-8.

[49] Hoonsopon, Danupol, and Guntalee Ruenrom. "The impact of organizational capabilities on the development of radical and incremental product innovation and product innovation performance." Journal of Managerial Issues 24, no. 3 (2012): $250-276$.

[50] Hair, Joseph F., William C. Black, Barry J. Babin, Rolph E. Anderson, and R. Tatham. "L. (2010). Multivariate Data Analysis." Multivariate Data Analysis. Pearson (2010).

[51] Fabian, Tomas. "Fostering innovation through organizational agility in the technology-driven firm: an exploratory case study in the media industry." Master's thesis, 2019. Available online: https://openaccess.nhh.no/nhhxmlui/bitstream/handle/11250/2678797/masterthesis.pdf?sequence=1 (accessed on March 2021).

[52] Bočková, Kateřina, Jana Škrabánková, and Michal Hanák. "Theory and Practice of Neuromarketing: Analyzing Human Behavior in Relation to Markets.” Emerging Science Journal 5, no. 1 (February 1, 2021): 44-56. doi:10.28991/esj-2021-01256.

[53] Liu, Sen, Yang Yang, Wen Guang Qu, and Yuan Liu. "The Business Value of Cloud Computing: The Partnering Agility Perspective.” Industrial Management \& Data Systems 116, no. 6 (July 11, 2016): 1160-1177. doi:10.1108/imds-09-2015-0376.

[54] Gassmann, Oliver, Ellen Enkel, and Henry Chesbrough. “The Future of Open Innovation.” R\&D Management 40, no. 3 (February 23, 2010): 213-221. doi:10.1111/j.1467-9310.2010.00605.x. 